attracted about US $\$ 1.1$ billion in funding from the National Institutes of Health in 2017. The US $\$ 1.7$ billion allocated to the entire state trails only California and Massachusetts.

In the past few years alone, advances in precision medicine, the development of new treatments for hepatitis $\mathrm{C}$, and discoveries about the microbiome have only been possible due to the ingenuity of scientists at New York-based institutions. At Columbia University - New York's top-contributing institute to the index - researchers recently developed a method for storing up to 215 petabytes of information in a gram of DNA. In a preliminary test, they were able to encode, and then retrieve, an entire operating system, a movie and several files in a string of nucleotides.

\section{PAYING UP}

Despite its scientific cache, New York has struggled to lure many new businesses. The city's high living cost has made it difficult for cash-strapped start-ups to find adequate lab and office space. According to data from the Bureau of Economic Analysis from 2015, the New York metropolitan area (which includes nearby Newark and Jersey City, which are more affordable than Manhattan), is more than 20\% more expensive than the national average.

Institutions were also not making their hightech equipment readily available to entrepreneurs to help them cut costs. New York has 880 investment organizations, according to the Crunchbase database of start-ups, investors, and incubators, compared to 540 in San Francisco and 175 in Boston. But less money has been invested in New York-based companies, in part because the ecosystem is less mature and potential deals are often smaller, Thiede says.

So instead, founders opted to set up their companies in Silicon Valley and Boston, where well-established communities ensured better access to technology, affordable space was more abundant, and it was easier to catch investors' attention.

However, the scene in New York is changing, as the infrastructure needed to support young biotech firms is gradually being built up.

\section{INCUBATING SPACE}

In 2013, Sam Sia was looking for a space to set up his company, Junco Labs, which uses smartphones as diagnostic tools. Sia is a biomedical engineer at Columbia University. His research involves designing microfluidic systems that control the movement of liquids through tiny channels. In 2011, he published a paper in Nature Medicine on a cheap plastic microchip for diagnosing HIV and syphilis from blood samples. But when it came to establishing his company, he couldn't find a wet lab close enough to the university's northern Manhattan campus.

Another start-up expressed a similar need, prompting Sia and his wife, Christine Kovich, who had worked as a financial executive, to

\section{COMPANY TIES}

The number of bilateral collaborations between corporate and academic institutions in the life sciences in New York peaked in 2014 , based on an analysis of bilateral partnerships in the Nature Index.

\begin{tabular}{ll}
\hline Population $^{1}$ & $\mathbf{8 . 5 4 m}$ \\
\hline GDP per capita $^{1}$ & US\$63,200 \\
\hline R\&D as \% of GDP & \\
\hline Doctoral degrees $^{1}$ & $0.5 \%$ \\
\hline Patents granted $^{3}$ & $\mathbf{2 1 1 , 4 0 0}$ \\
\hline
\end{tabular}

\section{SHARE OF OUTPUT OVER TIME}

New York's contribution to the share of authorship in the Nature Index, measured by the share of weighted fractional count (WFC) for that year, compared to the United States as a whole.

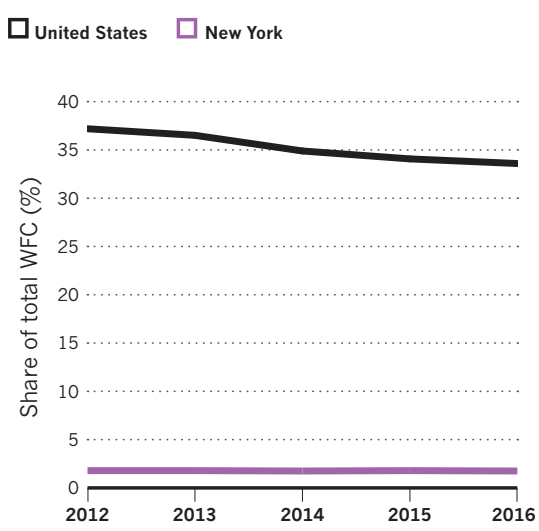

\section{SUBJECT STRENGTHS}

Most of New York's contribution to the authorship of papers in the Nature Index is in the life sciences.

\section{United States $\square$ New York Output is based on WFC 2016}

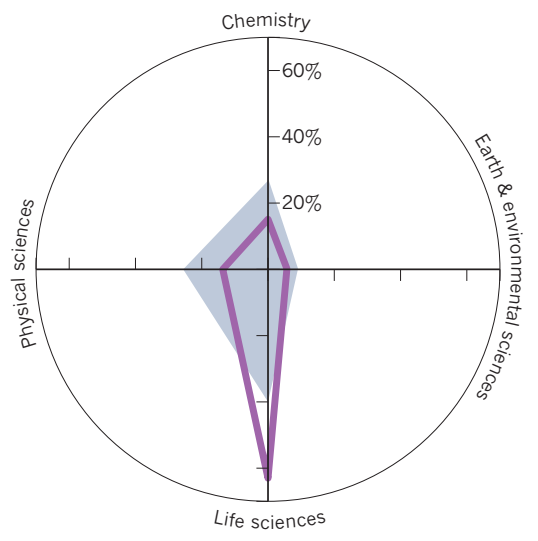

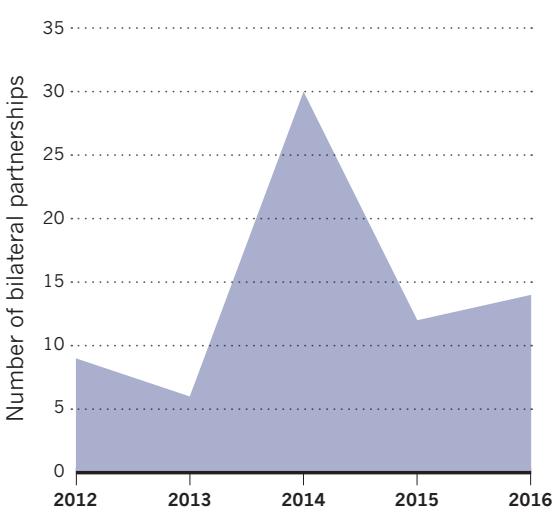

FINANCING BIOTECH

After an initial surge, investment in biotech companies in New York has declined since 2015.

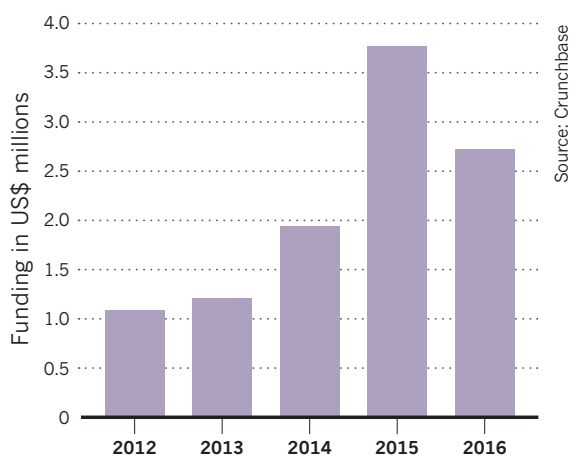

\section{STARTING UP START-UPS}

The number of new biotech and life sciences start-ups created in New York has been steadily declining since 2013.

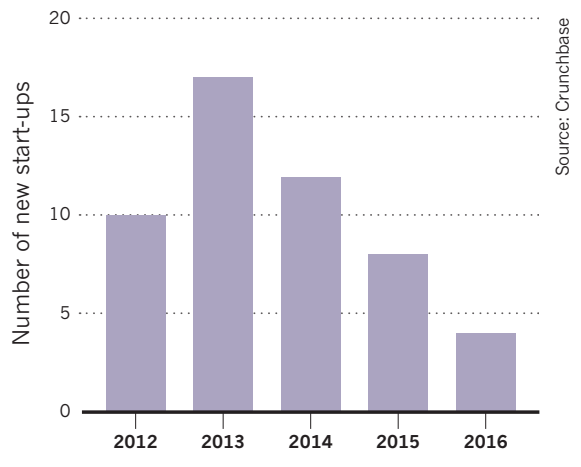

1. United States Census Bureau (population 2016 data, GDP per capita and science doctorates 2015 data) 2. National Science Foundation \& US Census Bureau (2015) 3. United States Patent and Trademark Office (2016) 


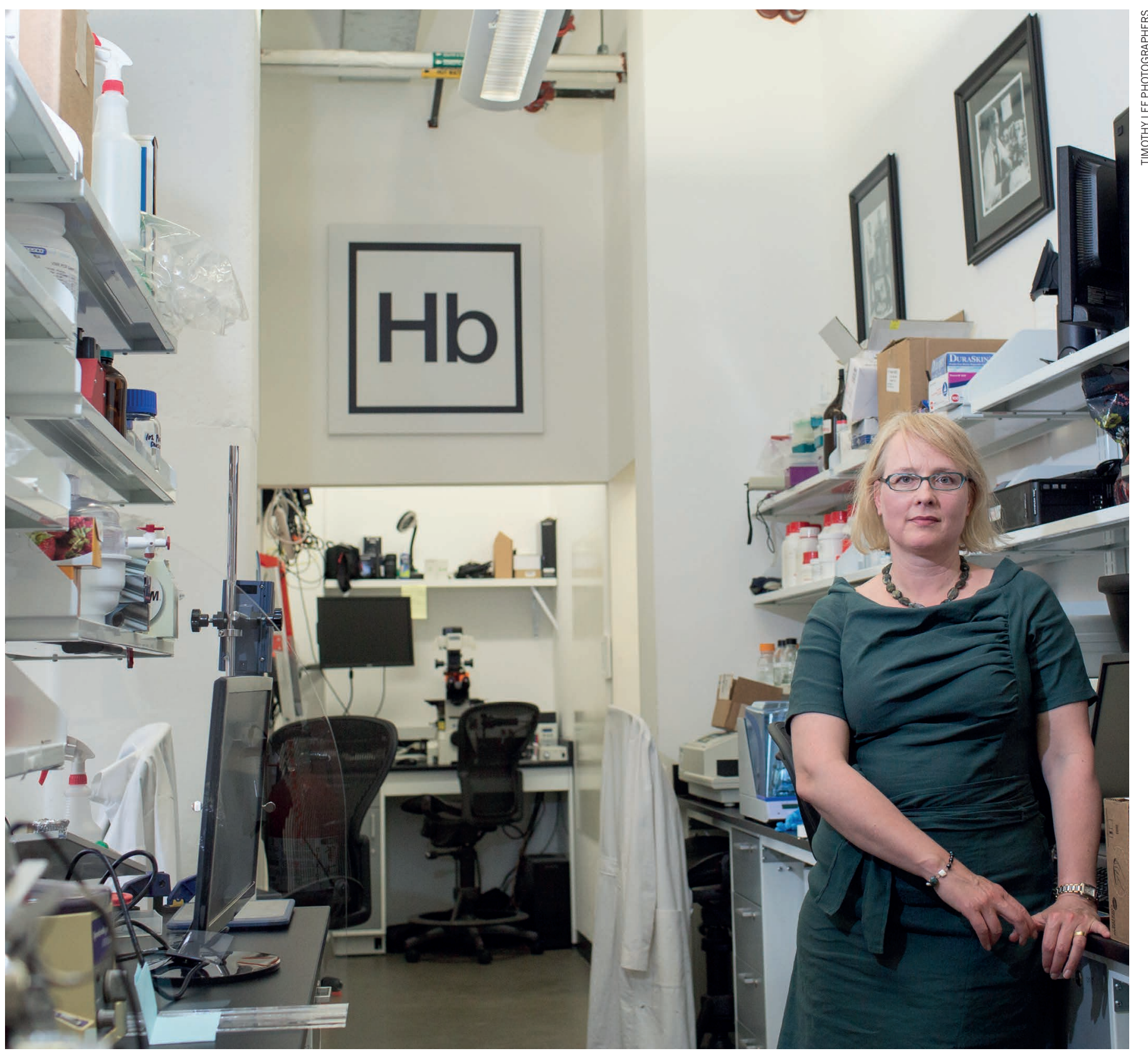

Christina Kovich, co-founder of the biotech incubator Harlem Biospace, who set up the space with her biomedical engineer husband to fill a gap in the sector.

found the biotech incubator Harlem Biospace. Within two months, the pair had opened a facility offering a six-month slot for a desk, wet lab space, entrepreneurial mentorship, and shared equipment at a cost of less than US $\$ 1,000$ per month.

Incubators offering shared equipment and mentorship for new companies, sometimes in exchange for a stake in those companies, are springing up all over New York. Designated funding sources have also been established to boost the growth of young companies Accelerate NY Seed Fund, for example, backs young life science start-ups with an average investment of US\$200,000.

"You can no longer say that there's a shortage of good, cheap lab space," says Nadim Shohdy, assistant dean and director of the NYU Office of Therapeutics Alliances, a programme created to convert biomedical research from NYU into new biotech start-ups.

\section{"THEQUESTION HAS ALWAYS BEEN, WHY NOT NEW YORK?"}

Local and state governments have also made substantial investments to promote the life sciences and biotechnology. In December 2016, NYCEDC unveiled LifeSci NYC, a
US\$500 million initiative that aims to create 16,000 jobs in the life sciences over the next decade. The money will be funnelled into the industry in the form of tax incentives (US\$300 million), matching funds for early-stage business (US\$20 million), and new incubators and facilities, including an applied life sciences campus (US\$100 million) to be located on the East River. That same month, New York governor, Andrew Cuomo, announced a $\$ 650$ million initiative made up of tax benefits, grants, and investment to support new and growing biotech and life sciences companies state-wide.

In 2014, biophysical chemist Rein Ulijn became director of the Nanoscience Initiative at City University of New York (CUNY), moving from the United Kingdom to the United 
States to take up the position. Ulijn brought along his start-up, Biogelx, a company that makes gel matrices for lab-based cell cultures. "I moved to New York because I could see that there was a lot of enthusiasm and investment around developing a stronger academic presence, and with that, a stronger entrepreneurial and start-up culture," he says.

Biogelx has its offices in Harlem Biospace, a few blocks from Ulijn's academic research labs.

\section{FITS AND STARTS}

But the influx of money and creation of cheap lab space might not be enough to make New York the next biotech destination, says NYU's Shohdy. He describes the city's biotech scene as organized chaos, growing in fits and starts.

The funds, he says, would be more effectively spent if they were tied to targets for success, such as how many companies they want to have backed over a given period.

According to data from Crunchbase, the number of life science and biotech start-ups created in New York City over the past five years peaked in 2013 with 17 start-ups, and has steadily decreased every year since then to 4 in 2016.

Though investment in New York life science and biotech companies more than doubled between 2012 and 2015, increasing from US $\$ 111$ million to US $\$ 383$ million, it dipped to US\$276 million in 2016.

If 2017 continues to average the same investment per month as it had through July, it will decline to about US\$268 million, a drop of nearly US\$9 million from the year before.

Taking Ulijn's company as an indication, however, New York's time might come soon. Product sales at Biogelx have grown steadily, in part because the company has many customers in the city they can meet with face-to-face. The company is here to stay and is even considering expanding its presence in New York. Ulijn is convinced that the ecosystem is poised for growth. "It's going to happen. There's enough in place that makes it difficult to see the momentum not continuing."

\section{INTER-CITY COLLABORATIONS}

This map shows the top ten collaborations between pairs of institutions based in New York. Seven institutions account for the ten most productive partnerships in the index, ranked by their collaboration score (CS), which sums the share of authorship for each institution in papers they have co-authored. Bubbles represent an institution's total contribution to the share of authorship in the index, measured by weighted fractional count (WFC).

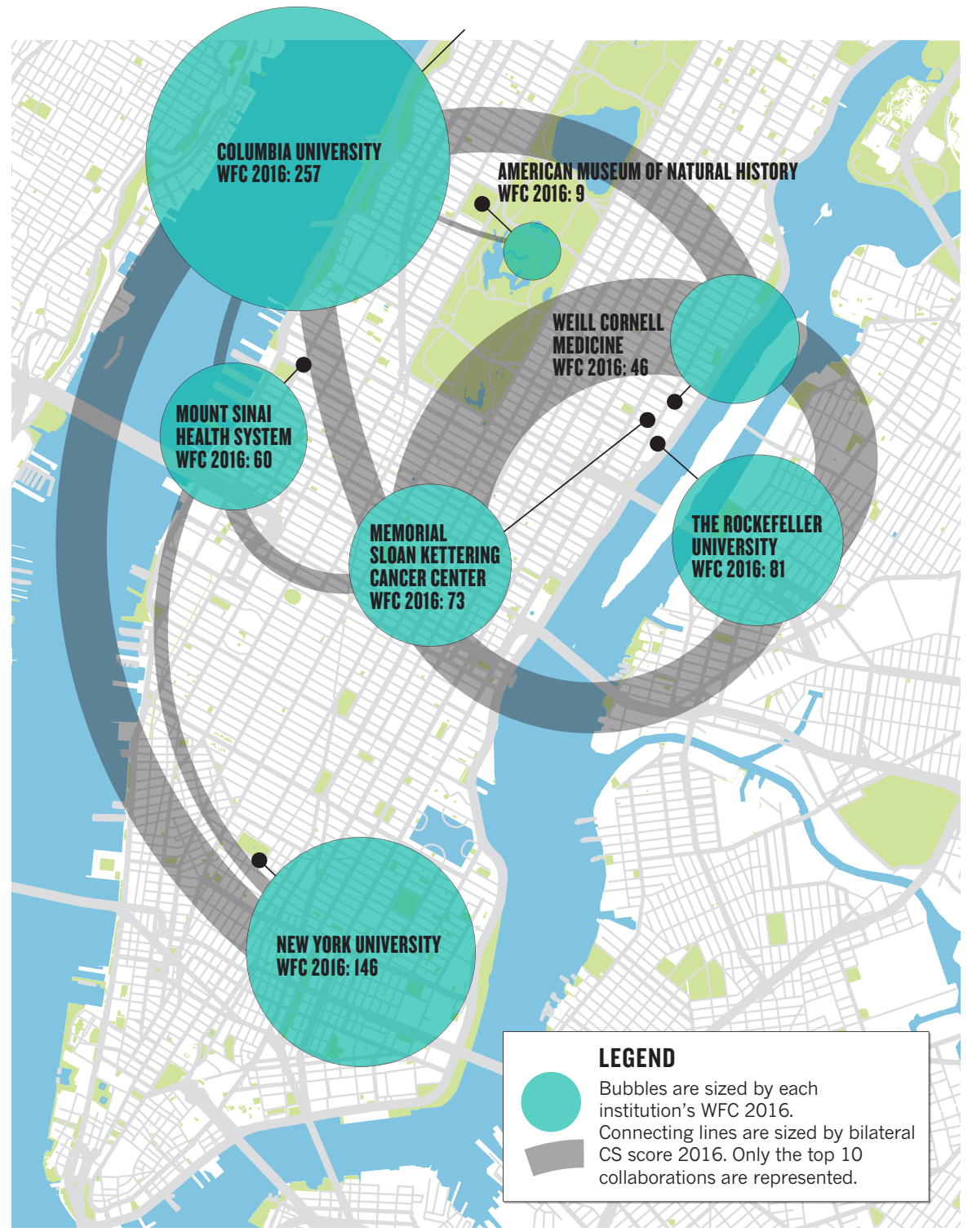

\section{TOP 10 INSTITUTIONS IN NEW YORK}

\begin{tabular}{|c|c|c|c|c|c|}
\hline RANK & INSTITUTION & WFC 2012 & WFC 2016 & $\begin{array}{c}\text { CHANGE IN WFC } \\
2012-2016\end{array}$ & AC 2016 \\
\hline 1 & Columbia University in the City of New York & 257.0 & 256.7 & $0 \%$ & 905 \\
\hline 3 & The Rockefeller University & 73.7 & 80.6 & $9 \%$ & 220 \\
\hline 4 & Memorial Sloan Kettering Cancer Center & 87.9 & 73.3 & $-17 \%$ & 214 \\
\hline 5 & Mount Sinai Health System & 64.8 & 59.9 & $-8 \%$ & 208 \\
\hline 7 & Weill Cornell Medicine, Cornell University & 43.5 & 45.6 & $5 \%$ & 213 \\
\hline 8 & The City University of New York & 43.3 & 42.6 & $-2 \%$ & 166 \\
\hline 9 & Pfizer Inc. & 21.1 & 24.6 & $17 \%$ & 53 \\
\hline 10 & IBM Research & 48.5 & 13.0 & $-73 \%$ & 46 \\
\hline
\end{tabular}

